This item was submitted to Loughborough's Research Repository by the author.

Items in Figshare are protected by copyright, with all rights reserved, unless otherwise indicated.

\title{
Numerical representation of multiple premature failures in steel-plated RC beams
}

PLEASE CITE THE PUBLISHED VERSION

http://dx.doi.org/10.1142/S0219876217500359

\section{PUBLISHER}

(c) World Scientific Publishing Company

\section{VERSION}

AM (Accepted Manuscript)

\section{PUBLISHER STATEMENT}

This work is made available according to the conditions of the Creative Commons Attribution-NonCommercialNoDerivatives 4.0 International (CC BY-NC-ND 4.0) licence. Full details of this licence are available at: https://creativecommons.org/licenses/by-nc-nd/4.0/

\section{LICENCE}

CC BY-NC-ND 4.0

\section{REPOSITORY RECORD}

Khan, Mohammad Arsalan, Jamal El-Rimawi, and Vadim V. Silberschmidt. 2019. "Numerical Representation of Multiple Premature Failures in Steel-plated RC Beams". figshare. https://hdl.handle.net/2134/25060. 


\title{
Numerical Representation of Multiple Premature
}

\section{Failures in Steel-Plated RC Beams}

\author{
Mohammad Arsalan Khan ${ }^{*, \ddagger}$, Jamal El-Rimawi ${ }^{*}$, and Vadim V. Silberschmidtt, $, \dagger, \boldsymbol{\uparrow}$ \\ *School of Civil and Building Engineering, Loughborough University \\ Leicestershire, Loughborough LE11 3TU, UK \\ ${ }^{\dagger}$ School of Mechanical and Manufacturing Engineering, Loughborough University \\ Leicestershire, Loughborough LE11 3TU, UK \\ ${ }^{\ddagger}$ mohd.arsalan.khan@hotmail.co.uk \\ $\S_{j . a . e l-r i m a w i @ l b o r o . a c . u k}$ \\ ףv.silberschmidt@lboro.ac.uk
}

\begin{abstract}
Realizing the importance of widely used technique of plating for flexural retrofitting of reinforced concrete (RC) beams and its drawbacks due to premature failure(s), present work concentrates in developing a finite element tool model capable of successfully capturing multiple premature failure modes and their corresponding behaviors. The model is simple but focused; the capability and accuracy of the results have been validated through test literature, particularly focusing on the load capacities of beams at progres-sive stages of failure modes; which is from crack initiation through to complete failure, such as the load of crack initiation, first crack and complete failure. Acceptable accu-racy is shown in terms of crack type(s), crack patterns, sequence, location and direction of propagation through the innovative use of cohesive zone model (CZM). The model clearly explains that debonding and peeling, although originating from a same location for most cases, are extensions of different types of cracks.
\end{abstract}

Keywords: Premature failure; cohesive zone model; retrofitting; debonding; peeling.

\section{Introduction}

A need for strengthening reinforced concrete $(\mathrm{RC})$ beams may arise for several reasons. For example, deterioration of a beam with time and/or chemical attacks may cause loss of material strength; or a requirement may arise to upgrade an existing beam to carry extra load. In this direction, a pioneering study of epoxy-bonded steel plates was carried out in 1967 [L'Hermite and Bresson (1967)]. Due to economic and aesthetic reasons, plating method(s) has been widely used for strengthening of RC beams [Hamoush and Ahmad (1990b); Hussain et al. (1995); Oehlers (1992);


Aligarh Muslim University, Aligarh 202002, Uttar Pradesh, India 
Oehlers et al. (1998); Swamy et al. (1987); Swamy et al. (1989)]. Although, external plating is found to improve ultimate strength, increase in flexural stiffness, and to reduce cracking and structural deformations in comparision to unstrengthened beams [Almusallam and Al-Salloum (2001); Jones et al. (1982, 1988); Saadatmanesh and Ehsani (1991); Sevuk and Arslan (2005); Swamy et al. (1987); Swamy et al. (1989)]; however, critical limitations have challenged the confidence in the use of such methods. Formation of premature cracks is found to overtake the behavior of a beam and a cause of catastrophic failure. In this direction, a number of analytical [Adhikary et al. (2000); Teng et al. (2002); Smith and Teng (2001); Ye (2001); Raoof et al. (2000); Raoof and Hassanen (2000)], experimental [Hamoush and Ahmad (1990a); Hussain et al. (1995); Jones et al. (1988); Oehlers (1992); Oehlers and Moran (1990); Roberts (1989); Sharif et al. (1994); Swamy et al. (1987, 1989); Zhang et al. (1995); Ziraba et al. (1994); Heathcote (2004); Charif (1983); Oh et al. (2003b); Yao (2004)] and numerical [Coronado and Lopez (2006, 2010); Godat et al. (2012); Teng et al. (2002); Chen et al. (2011); Alfano et al. (2010); Rahimi and Hutchinson (2001)] studies have been conducted. Experimental evidences indicate that the modes of failure are dependent on beam parameters. However, due to the limitations of laboratory tests, such as cost, stress-strain distribution within beam, material damage, control over boundary conditions, influence of beam parameters and the accuracy of results, researchers [Arslan et al. (2008); Oh et al. (2003b); Yang et al. (2003)] have adopted finite element modeling methods. However, due to the lack of literature to suggest problem specific methodologies, the behavior of failure modes and the contribution of beam parameters are far from being clear. Another study [Neto et al. (2016)] has shown that as compared to unidirectional loading in mode-II direction, application of mixed-mode stresses can significantly reduce the strength of interface. Therefore, a 4-point loading problem is considered for comparing different modes of failure under mixed-mode stress distributions. A new modeling approach [Khan (2014)] is validated against the literature in terms of crack type, location of crack, load of crack initiation, load of complete crack, direction of crack propagation and sequence of cracks. In contradiction to a popular assumption in literature, this study has identified reasons for peeling as a completely different mode of premature failure from debonding.

\subsection{Description of crack modes}

Premature brittle failures that are unique to plated beam consist of interface failure at mid-span and plate-end, cover rip-off at plate-end; and desired mode of ductile failures, that is yielding of steel - external, internal or both. The other modes of non-premature and brittle failures include crushing of concrete in compression and shear failure.

The modes of failures in relation of their failure type, location and propagation can be schematically summarized in Fig. 1. Debonding and peeling failures are identified in relation to interfacial and flexural cracks, and classified in Table 1 


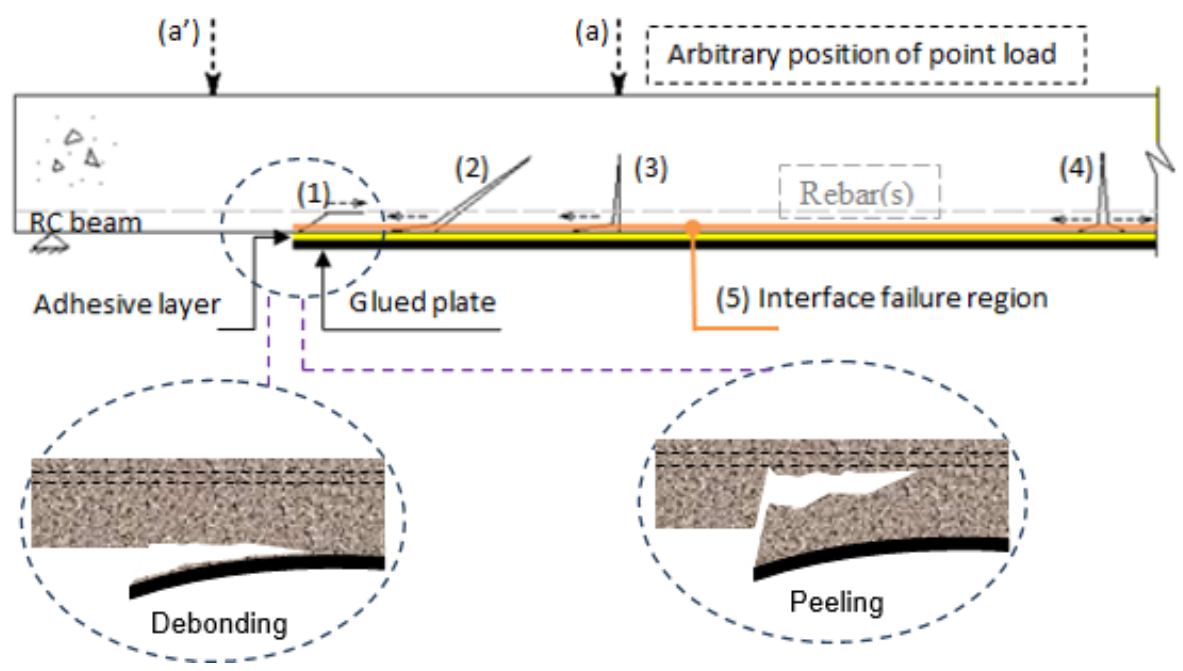

Fig. 1. Premature failure modes on plated RC beam at soffit for arbitrary position of point load (1) peeling, (2) diagonal crack in tension-DC, (3) flexural crack-FC, (4) pure flexural crack-PFC and (5) interface cracking-debonding.

including the reasons and some favorable conditions of occurrence. Debonding occurs when $\operatorname{crack}(\mathrm{s})$ develop along the adhesive-concrete interface. Peeling is spotted at plate-end region, mainly as a consequence of unusual (and isolated) formation of flexural crack and its subsequent propagation.

Cracks 3 and 4 are flexural cracks that develop to form interfacial cracks (crack 5$)$. In case of crack 2 , in a beam with low shear capacity, a major diagonal crack (DC) will cause collapse.

A peeling failure can be easily visualized but not easy to quantify (Saadatmanesh and Malek, 1998). Coronado [2006] specifically dealt with peeling mode of failure for FRP plated RC sections using a damage band approach (smeared cracking) embedded in Abaqus. However, the drawback of damage band approach is that it is complex and case sensitive in terms of load-displacement behavior. Therefore, unlike the works of Jumaat and Alam [2008], Adhikary and Mutsuyoshi [2002], Arslan et al. [2008], Oh et al. [2003a] and Ziraba and Baluch [1995], cohesive element foundations are used through a novel approach to capture the effect of material properties on cracks and to differentiate between plate-end debonding and peeling.

\section{Material and Numerical Model}

A gap in the literature is covered by incorporating an adhesive layer for its material and geometrical properties. The choice of concrete damaged plasticity model for concrete and the cohesive zone model (CZM) for adhesive are capable to retain damage to indicate closeness to real conditions. In addition, unlike smeared crack model, concrete damaged plasticity model assumes the retention of permanent plastic strain 


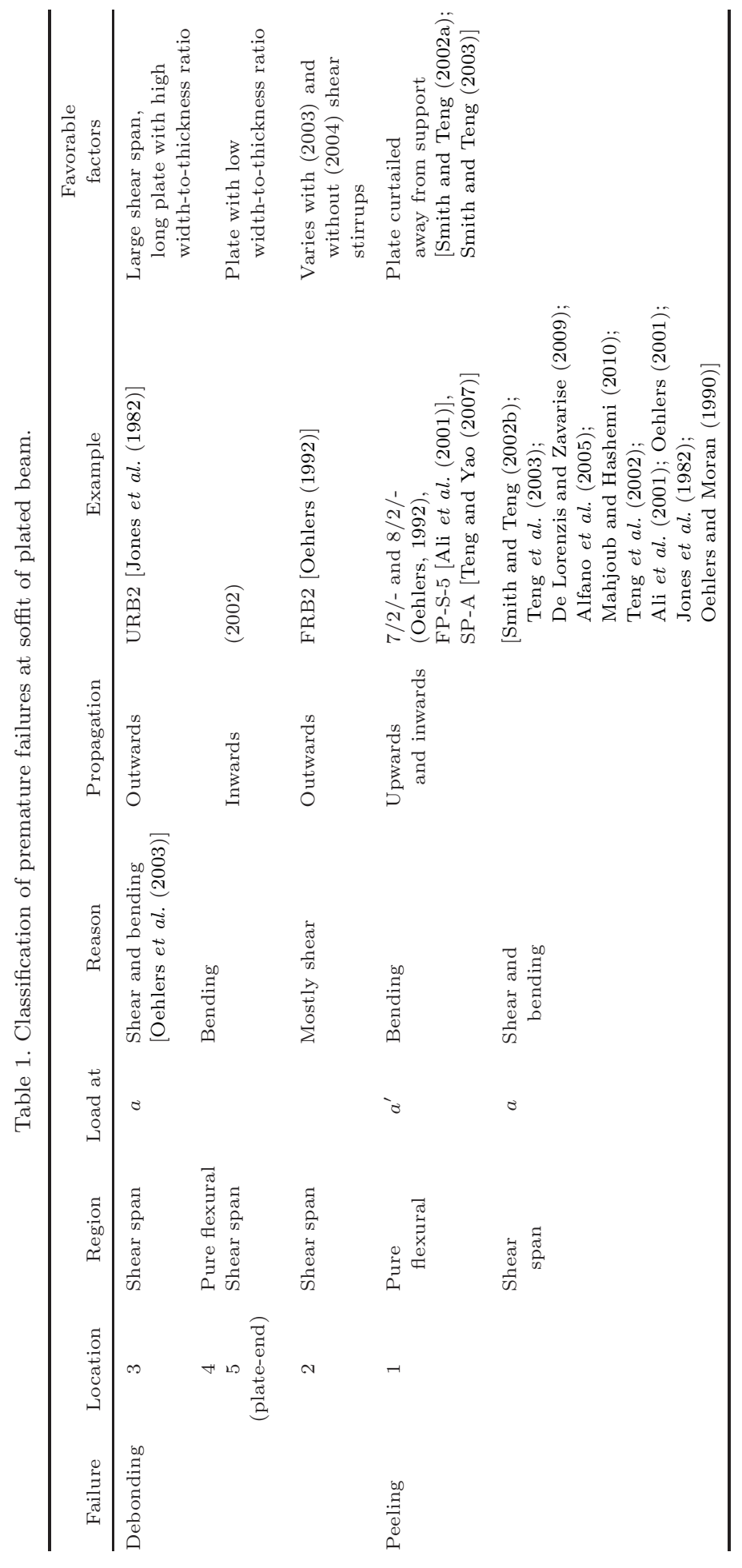


(not total strain values) after damage initiation (both in tension and compression concrete).

\subsection{Concrete}

Concrete has been defined as a quasi-brittle material using concrete damaged plasticity approach that defines the crack band model based on the proposition by Lubliner et al. [1989] and Lee and Fenves [1998] controlled by two hardening variables linked to failure mechanisms under tension and compression loading. This model uses a concept of isotropic damage elasticity in combination with isotropic tensile and compressive plasticity to represent the inelastic behavior of concrete. In case of unloading and reloading or cyclic loading, such as the effects of stress redistribution, this model also accounts for stiffness recovery.

A uniaxial stress-strain material behavior is simplified as shown in Appendix. Similar approach was adopted by Kachlakev et al. [2001]; however, they used predefined stress-strain behavior for concrete in compression. In compression, softening is maintained until initiation of crushing [Shah et al. (1995); Shanmugam and Baskar (2008)], and the loss in strength afterwards [Bangash (1989)] is not deemed as a premature failure. According to Bontempi and Malerba [Bontempi and Malerba (1997)], dilation angle $\psi$ and Poisson's ratio $\nu$ are assumed to be $31^{\circ}$ and $0.12^{\circ}$, respectively.

Following Lubliner et al. [1989], in order to model tensile flexural crack in concrete, Abaqus assumes that cracking initiates at points where the tensile equivalent plastic strain is greater than zero, $\tilde{\epsilon}_{t}^{\mathrm{pl}}>0$, and the maximum principal plastic strain is positive. For example, to capture crack for the specimens of Oh et al. [2003b], the minimum value for principle strain is evaluated at 0.001 (that is, elastic strain limit) and the complete crack forms at 0.003 .

To demonstrate cracks or plastic strains in tension, the linear softening energy criteria is adopted as:

$$
G_{f c}=0.5 \epsilon_{o} f_{t} b
$$

where $G_{f c}$ is crack energy, $\epsilon_{o}$ is tensile strain on element width of $b$ and $f_{t}$ is tensile stress.

\subsection{Steel}

Steel (isotropic material) has been considered to be elasto-plastic in nature with bilinear (for rebar) and trilinear (for plate) behavior mainly in accordance to British Standard Institution [1990]. Shear stirrups are avoided in reference to Oehlers [Oehlers (2001)], as the shear reinforcement is found to be ineffective to prevent crack, such as DC. To accommodate for this, beam is not designed to fail in shear as this is not considered as a premature failure. 


\subsection{Adhesive layer}

A traction-separation approach is utilized at interface for CZM to suit available experimental data for simulating models of the corresponding literatures. So as to capture interfacial cracks, a layer of cohesive elements are embedded along a critical zone (crack 5 region in Fig. 1). A critical zone identified is based on literature review.

Unlike researchers [Adhikary and Mutsuyoshi (2002); Ziraba and Baluch (1995)] that considered bond behavior as linear elastic-brittle, in the current study the material properties for a cohesive layer are adopted for a mixed-mode behavior of adhesive and a crack. A bilinear material behavior demonstrates a linear-elasticity until initiation of damage and a linear damage evolution afterwards, as shown in Fig. 2. Poisson's ratio for adhesive is taken as 0.16 [Ziraba and Baluch (1995)].

A damage parameter $\left(D_{m}\right)$ is assigned to describe the state of cohesive element evolving from 0 (no damage) to 1 (failure) based on a damage evolution rule:

$$
D_{m}= \begin{cases}0, & \delta_{m} \leq \delta_{m}^{\circ}, \\ \frac{\delta_{m}^{f}\left(\delta_{m}^{\max }-\delta_{m}^{\circ}\right)}{\delta_{m}^{\max }\left(\delta_{m}^{f}-\delta_{m}^{\circ}\right)}, & \delta_{m}^{\circ}<\delta_{m}<\delta_{m}^{f}, \\ 1, & \delta_{m} \geq \delta_{m}^{f},\end{cases}
$$

where $t_{m}$ is a mixed-mode stress transferred across the surfaces of a crack, and $\delta_{m}$ is a mixed mode displacement at any instant. At $\delta_{m} \geq \delta_{m}^{f}, D_{m}=1$ and $t_{m}=0$; this implies that an interface element has fully failed to transfer any further stresses across its boundaries.

Initially, it was noted by Ascione and Feo [2000] that in addition to large amount of transverse stresses, significant amount of normal stresses are also developed near plate-end (not at plate-end) that may contribute to crack at plate-end. Therefore, to further verify and build on the work of Ascione and Feo [2000], a current approach incorporates bond mechanisms both for normal and transverse interactions.

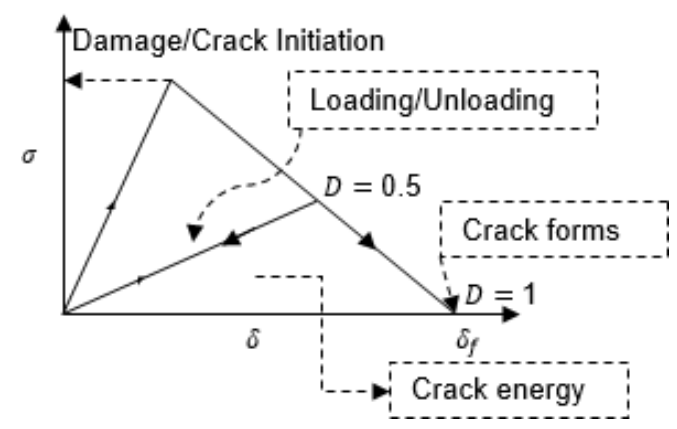

Fig. 2. Linear damage behavior for cohesive element as adopted in Abaqus. 


\subsection{FE model}

The numerical analysis herein is a two-dimensional (2D) nonlinear finite element analysis, verified through theoretical models and validated across a wide experimental literature by Khan [2014]. Primarily focussing on cracks, a 2D planestress approach is adopted for simulations by means of a commercially available FE software package [ABAQUS (2011)], executing on a Microsoft Windows operating system. This analysis is a nonlinear static procedure with a classical full-Newton solving method. Element type for concrete and steel is a quadratic quadrilateral 2D continuum element with reduced integration (CPS8R); while a four-noded 2D cohesive element (COH2D4) is adopted for adhesive.

Steel plate and equivalent rebar sections are modeled with matching element sizes. To observe formation of cracks, cohesive layer is assigned a finer mesh (with unity base width). A meshed model, with boundary conditions, is shown in Fig. 3 .

Loading and Boundary Conditions: Half-beam is provided with $y$-axis symmetry at the middle of the beam along the sectional depth. Support plates are provided in order to prevent load punching and with an advantage of having a free rotation. To avoid stress concentration and numerical instability, a relatively finer mesh is considered at support/load plates. Inducing loads in the form of displacements at load plates (rather than directly applying loads in MLT-2) reduced the time of analysis. To regulate accuracy on results, load increments are adjusted such that an initial increment is kept at $10^{-5}$ and a maximum increment at $10^{-2}$.

Concrete and Steel: The total number of nodes (elements) used to generate the models for specimens of Jones et al. [1982] are 4,352 (1715) and 1,917 (584) for plated and unplated sections respectively, while 5,065 (1957) and 2,575 (800) for plated and unplated specimens of Jones et al. [1982] and, 2,611 (814) and 4,871

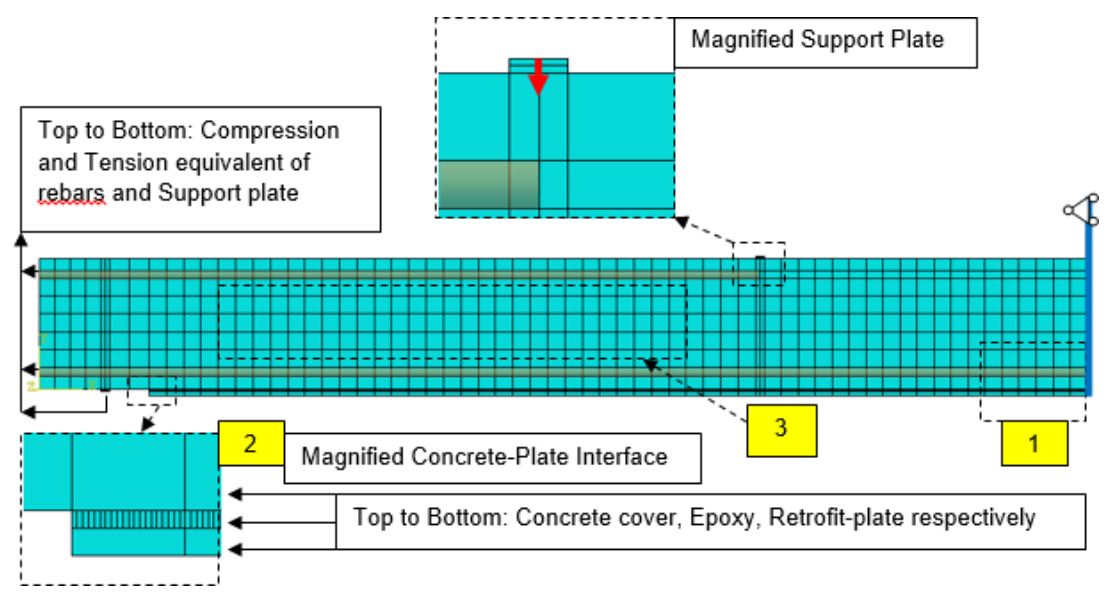

Fig. 3. M20 mesh layout for plated beam and boundary conditions. 
(1864) for unplated and plated specimens respectively for Oh et al. [2003b]. In real situations, the cracks/debonding are not due to perfect delamination of the two interfaces, it can rather be close to a perfect interface. Therefore, a perfect bond has been assumed between the rebar section and the surrounding concrete; any damage in either of the materials are accommodated through their corresponding material models.

Adhesive: The cohesive elements are horizontally staked and tied to concrete elements on top and steel plate elements on bottom using surface-to-surface interaction/discretization method. CZM is adopted as a multipurpose methodology to indicate dimensions of adhesive (width and thickness), material properties for adhesive and/or concrete and the properties of crack.

\subsubsection{Mesh sensitivity}

As a plated beam has a different section to an unplated beam, mesh verifications are concluded on a former beam type to suit current investigations. Therefore, a plated beam URB4 [Jones et al. (1982)], having a balanced section, is picked for verifying mesh size; while different beam types (included unplated beam) are used for cross verification and validation studies.

Any alterations in element size would govern tensile fracture energy of concrete according to Eq. (2). More precisely, while fracture energy is also kept constant, the increase in element width to $B$ would redistribute the (original) cracking strain or fracture energy to a larger surface area $(B \times$ thickness of section); thereby, increase in $b$ directly contributes towards increase in load capacity. This argument is well supported from the plots shown in Fig. 4(a) with mesh sizes (vertical $\times$ horizontal) of $80 \times 80,60 \times 60,25 \times 25,20 \times 20,5 \times 5$ and unmeshed. Therefore, based on this, a value of $b$ would be identified to match the capacity of a corresponding beam in literature.

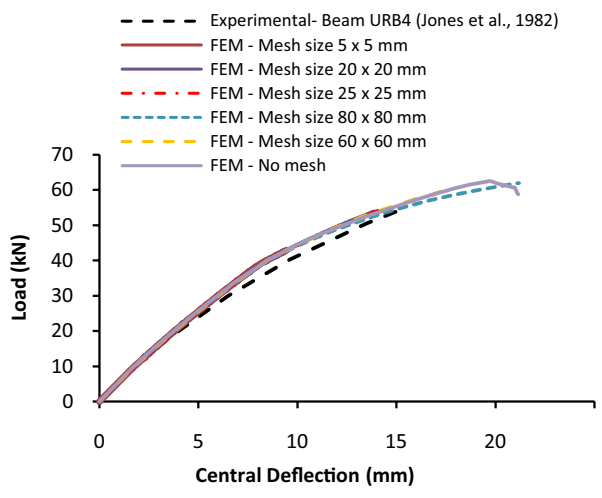

(a)

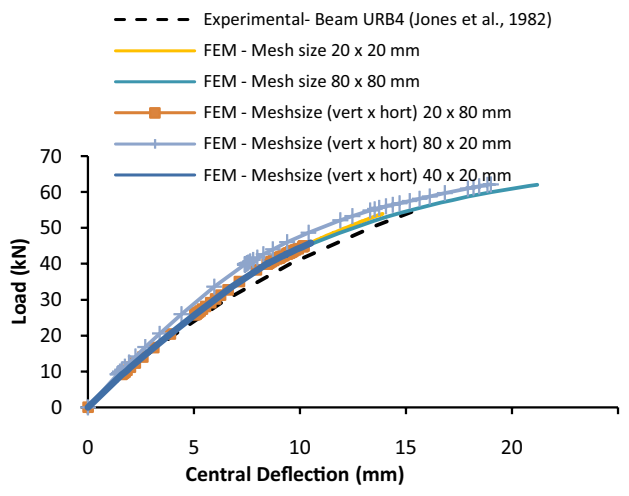

(b)

Fig. 4. Sensitivity for mesh sizes (a) overall mesh size and (b) element height and width. 
Additionally, it becomes important to check the effect of mesh size on overall behavior of beam (capacity and stiffening), while the input properties (including, fracture energy) are kept fixed. For different mesh sizes of $20 \times 20,80 \times 80,20 \times 80$, $80 \times 20$ and $40 \times 20$, Fig. 4 (b) indicates the effect of variation of mesh size on the overall load-deflection behavior of beam. Therefore, it is observed that changing the aspect ratio of element by increasing its vertical side would increase stiffness of beam. Matching real conditions, with acceptable accuracy, a mesh size of $20 \mathrm{~mm} \times$ $20 \mathrm{~mm}$ is also identified as a closer match to be around the size of the maximum aggregate size provided in the corresponding literature [Jones et al. (1982)].

\section{Results}

Subjected to scope, availability of data and a wide variety of work in the research field, validation studies are shown for 12 beams of Jones et al. [1982], Oh et al. [2003b] and Ashrafuddin [1995]. Selection of specimens covered a large range of variables, such as different beam sizes, material properties, shear span-to-depth ratio, adhesive line thickness, plate thickness, plate length, covercrete thickness and different failure modes.

Due to multiple types of premature cracks captured by Oh et al. [2003b], two specimens (S43S3 and S43S4) are numerically validated for premature cracks in this paper. However, debonding at mid-span is not demonstrated by them. Therefore, for completeness, a specimen URB2 by Jones et al. [1982] is considered for numerical representation.

\subsection{Specimens of Jones et al. [1982]}

Jones et al. [1982] tested eight beams of which three were under reinforced (including unplated beam URB1), one was balanced (beam URB4) and the remaining were over-reinforced with plate reinforcement. Combinations of theoretically underreinforced (URB1, URB2), balanced (URB4) and over-reinforced (URB5) specimens are modeled for numerical validations.

The initial stiffness of the experimental beam and FE model overlap (see Fig. 5(a)). The developments of longitudinal strains for plate and rebar are, respectively, validated in Figs. 5(b) and 5(c); a relatively lower strains are reported by numerical model until yielding. With the increase in load, the numerical beams with thinner plate are slightly stiffer than the experimental beams. However, with further increase in load, the numerical beams are softened until failure.

At first failure, the numerical load capacities (in $\mathrm{kN}$ ) for the beams URB1, URB2, URB4 and URB5 are 27.8, 36, 49.7 and 41.2, respectively, in close agreement with the corresponding experimental values of 28.1, 40.0, 55.9 and 49.6. The predicted mid-span displacements (in $\mathrm{mm}$ ) of 19.87 for URB1 and 7.2 for URB5 are in close agreement with those provided in literature, that are 19.81 and 10.5, respectively. It is quite evident that the error in the load carrying capacity increases for beams with thicker plates; this may be due to the instability of the FE model 


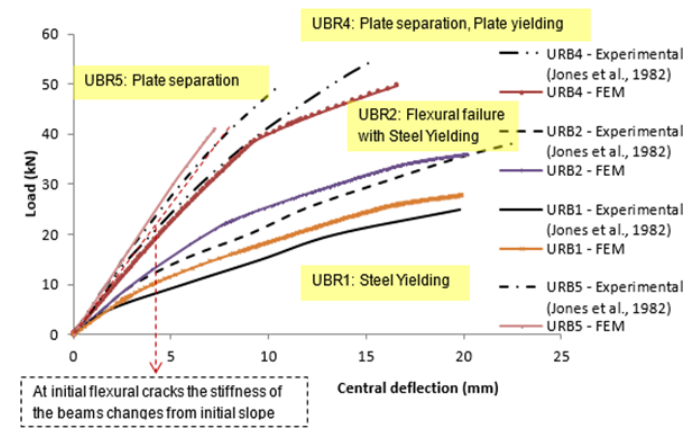

(a)

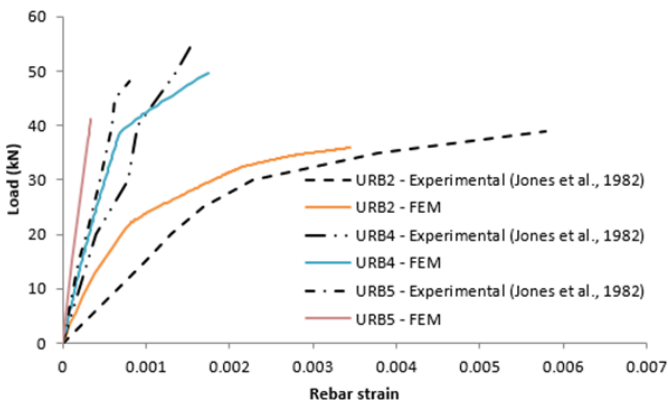

(c)

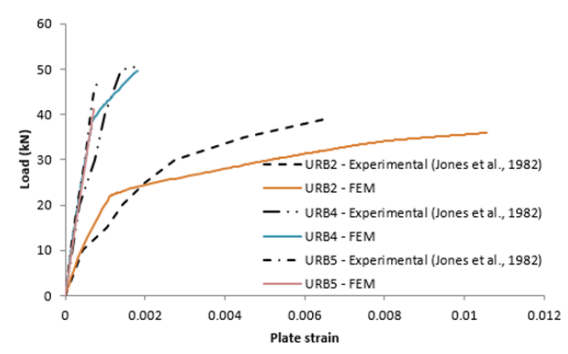

(b)

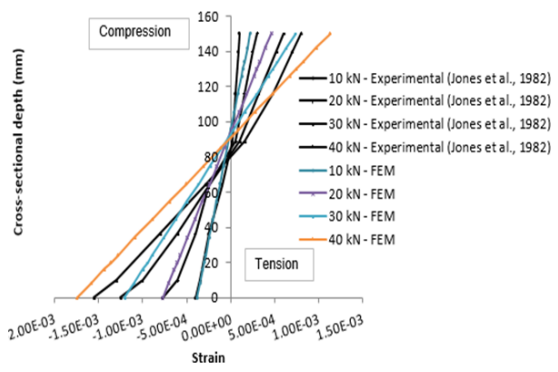

(d)

Fig. 5. (a) Load-deflection plots with modes of failure, (b) load versus longitudinal strain for plate at mid-span, (c) load versus rebar strains at mid-span in longitudinal direction and (d) longitudinal strain distribution across sectional depth.

after the appearance of premature cracks. However, in case of premature crack, it can be established that the load at first crack is of critical importance than the capacity of beam.

The cross-sectional strains in longitudinal direction for beam URB4 are validated in Fig. 5(d) at the loads of 10, 20, 30 and $40 \mathrm{kN}$. The relative difference of strains increased for numerical model with increased load. This may be due to relative increase in the ductility of numerical beam with increased loading (as seen in Fig. 5(a)). Although, beam URB4 is a balanced beam, the experimental strains suggest a change in neutral axis with load. As expected, in accordance of simple theory of bending, the FE model predicts a linear distribution of strains. Additional differences may also arise due to the inaccuracies in experimental methods.

Flexural crack (FC) modes of failure in flexural region (crack 3 in Fig. 1) and pure-flexural region (crack 4 in Fig. 1) have been captured for specimen URB2 taken from Jones et al. [1982]. The failure loads and modes of flexural failure (yielding of rebar) and mid-span debonding are in agreement with the literature. 


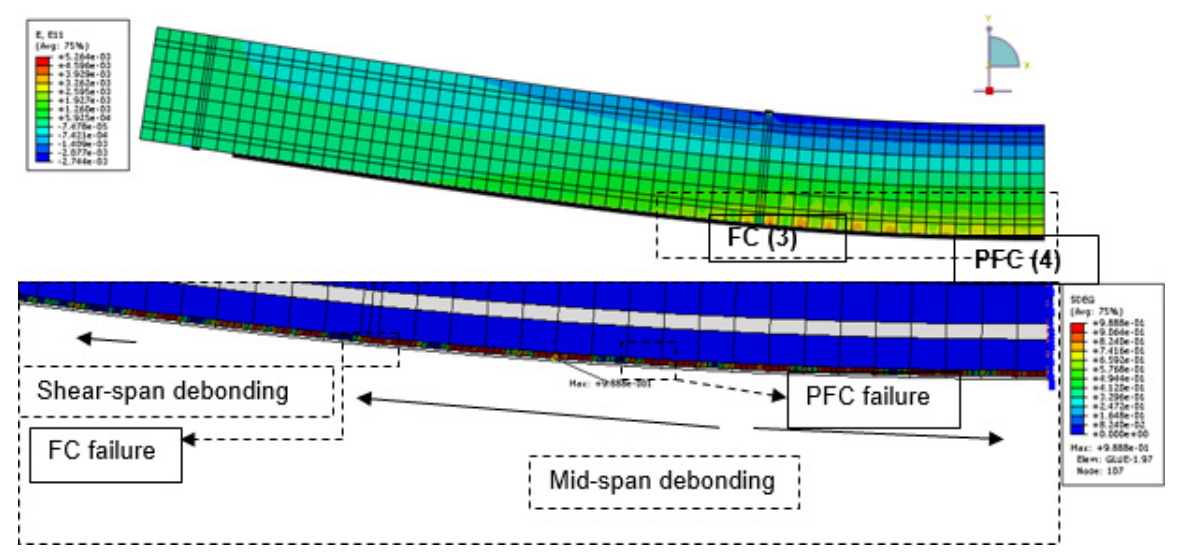

Fig. 6. Capturing FC mode of cracks and mid-span debonding (beam URB2).

In Fig. 6, with increasing load, the cracks are observed propagating outwards as captured by the damage patterns, whereas the balanced sections and over-reinforced beams failed by debonding at plate-end.

\subsection{Specimens of Oh et al. [2003b]}

In case of the beams of $\mathrm{Oh}$ et al. [2003b] undergoing plate yielding, plate separation and diagonal tension failures, the sequence of failure modes have been successfully captured for all 12 beams by Khan [2014]. However, due to space restrictions, results are shown for only four cases as in Table 2 and three beams in Fig. 7.

Exceptions are the shear compression failure that cannot be captured by the current model for beam S43S4. Though numerical model, specimen S43 is also seen to achieve plate yielding PY mode of failure; this is in addition to plate separation and DC.

A sequence of failure modes, captured by beams $\mathrm{S} 43 \mathrm{~S} 3$ and $\mathrm{S} 43 \mathrm{~S} 4$, consists of plate-end debonding (first premature failure), peeling and density of DC; the numerical presentation is shown in Fig. 8.

The debonding at plate-end occurred (at $132.2 \mathrm{kN}$ ) before a peeling crack (at $136.46 \mathrm{kN}$ ); this peeling crack propagates further diagonally towards forming a diagonal-tension crack. In Fig. 9, the location of peeling crack is highlighted. This behavior is due to high concentrations of localized stresses, which have initially resulted in the formation of flexural cracks at $100 \mathrm{kN}$ before plate starts to debond along the interface.

However, unlike beam S43S3, it is noticed that shorter shear span of beam S43S4 is subjected to increased density of DCs. Such behavior is not clearly identified by $\mathrm{Oh}$ et al. [2003b] as they noted that the DCs occurred with the separation of steel plates, whereas numerical observations indicate that the interfacial cracks are different from flexural cracks and to any corresponding propagation. 


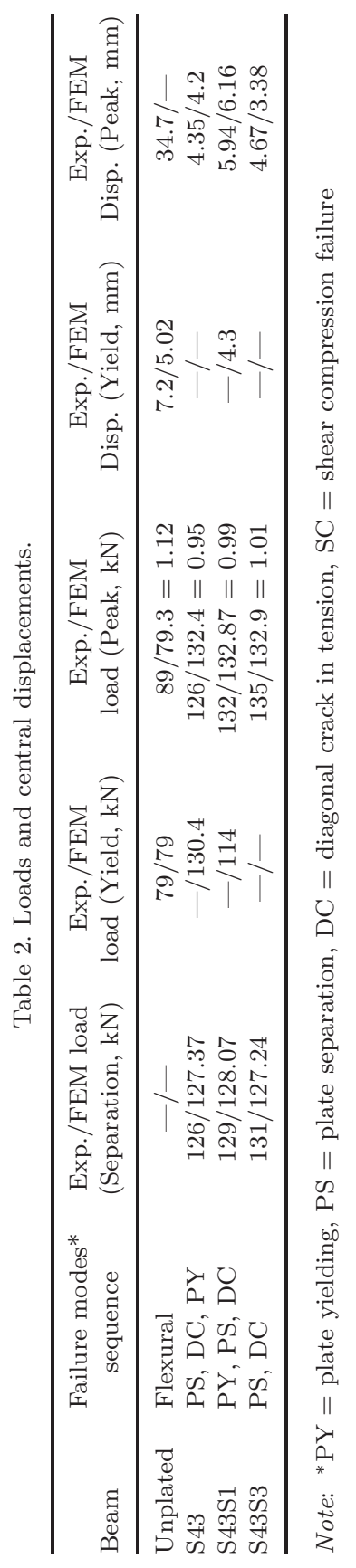




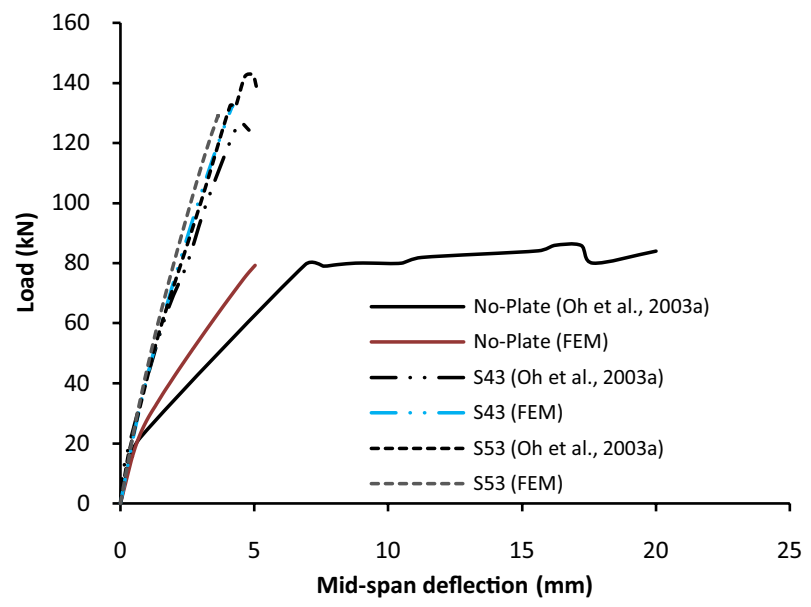

Fig. 7. Load versus central deflection validation.

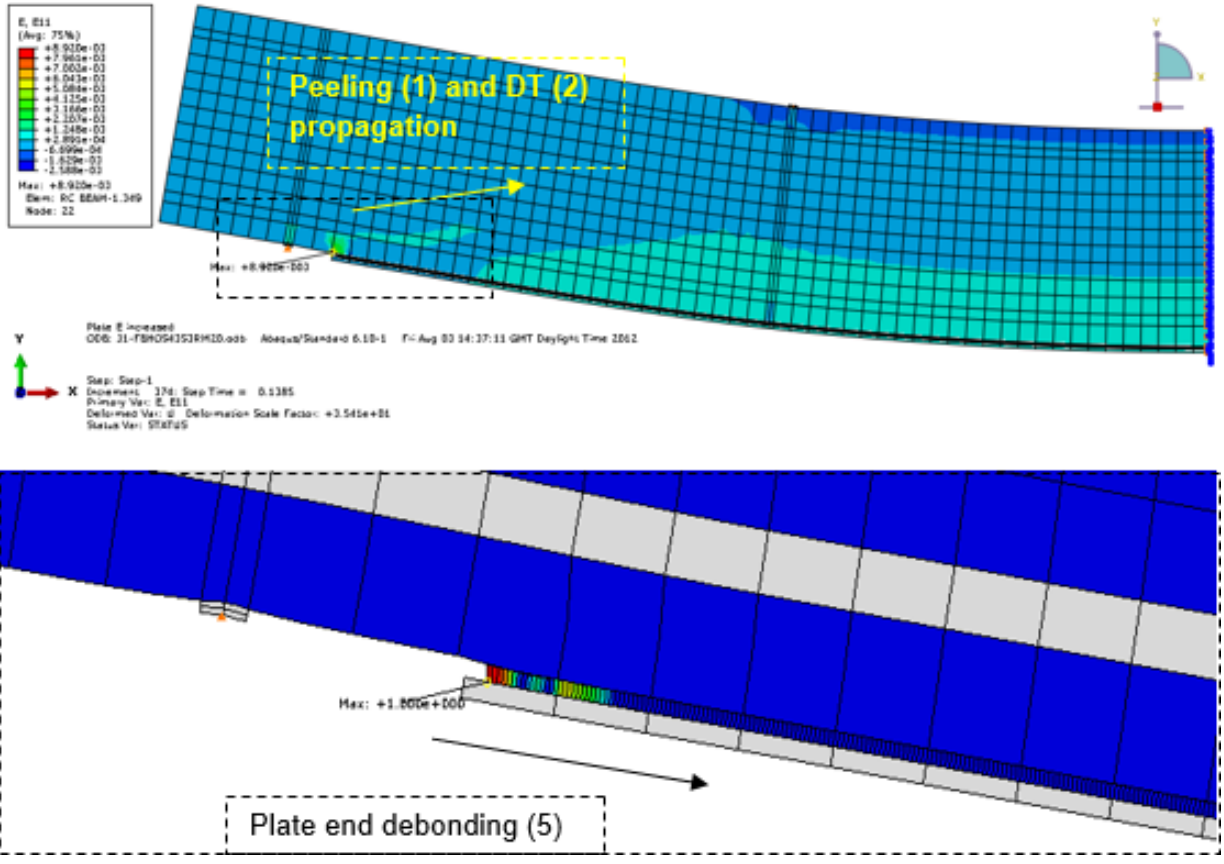

Fig. 8. Capturing plate-end debonding, peeling and tension-DC (beam S43S3).

\subsection{Specimens of Ashrafuddin [1995]}

To show the different modes of failures and the relevance of providing shear stirrups, specimens are picked from the series of F15, F21 and F115. Three modes of failures are seen, that is, flexural, peeling and mid-span debonding. The finite element 

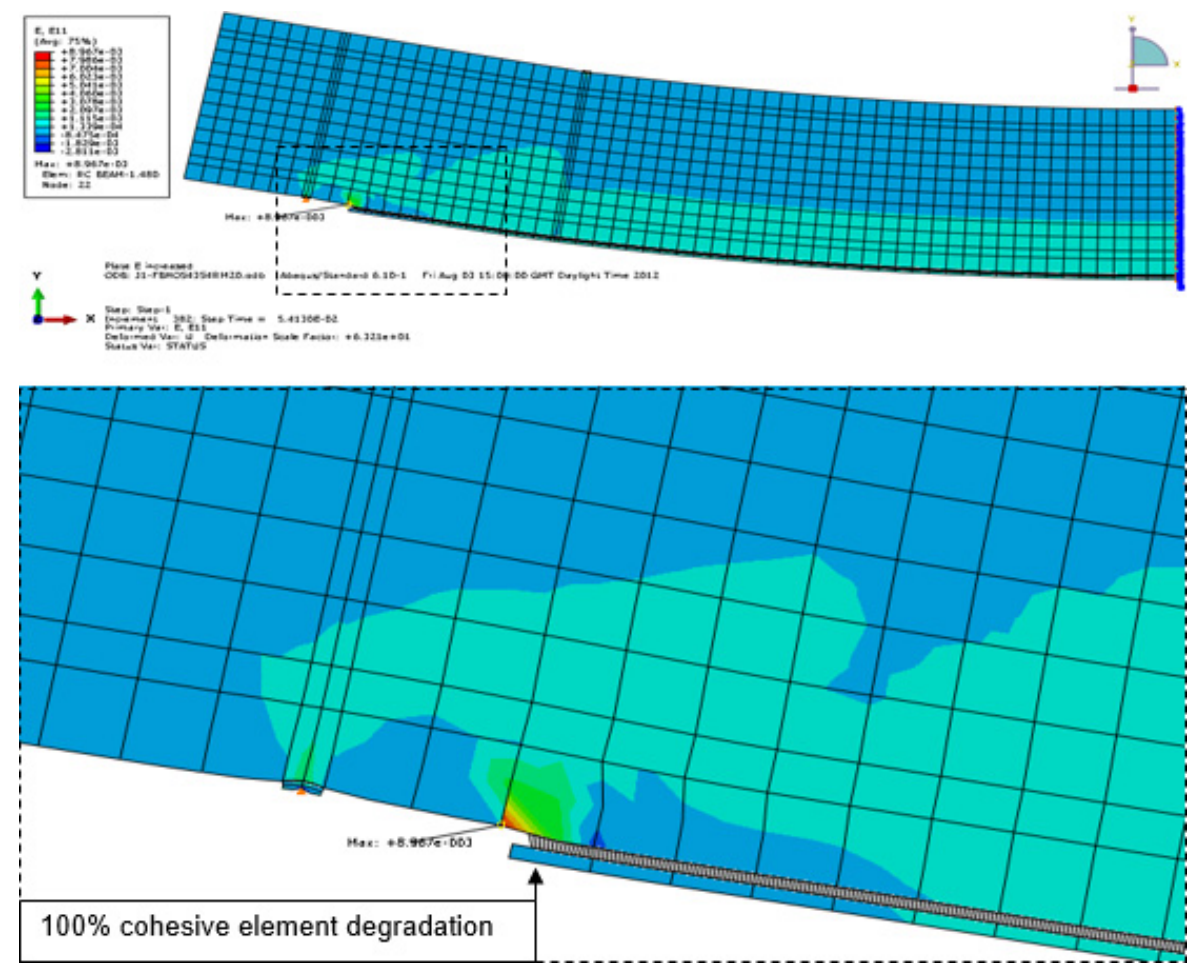

Fig. 9. Capturing peeling and crack density for DCs (beam S43S4).

method (FEM) sections (without shear stirrups) for F15, F21 and F115 matched closely with the behaviors of beam F1512, F256 and F1153, respectively, tested by Ashrafuddin et al. [1999] and Ashrafuddin [1995]. The load-deflection behavior is validated in Fig. 10. The load capacities and modes of failure are in close agreement with the results.

In addition, debonding cracks at mid-span for beam F156 (from series of beams F15) are clearly visible in the publication of Ashrafuddin et al. [1999]; however, such a mode of failure was not mentioned. Interestingly, this mode of failure is very well captured by the FE model for beam F1512 from the same series of F15 (not shown here to due to space restrictions); the cohesive elements are degraded. It is also observed that the debonding cracks that appeared at mid-span propagated outwards.

Unlike F115 range, the behavior for F15 and F25 ranges was similar among each set [Ashrafuddin (1995)]. Therefore, a section with $1 \mathrm{~mm}$ plate thickness and $150 \mathrm{~mm}$ of curtailment length is compared with the results of Ashrafuddin et al. [1999] for varied shear stirrup spacings (30,60 and $120 \mathrm{~mm})$ in Fig. 10. The results obtained by FE model for F115 range are in closest agreement with F1153, that is, stirrups are very closely placed (that is, $30 \mathrm{~mm}$ compared with $60 \mathrm{~mm}$ and $120 \mathrm{~mm}$ 


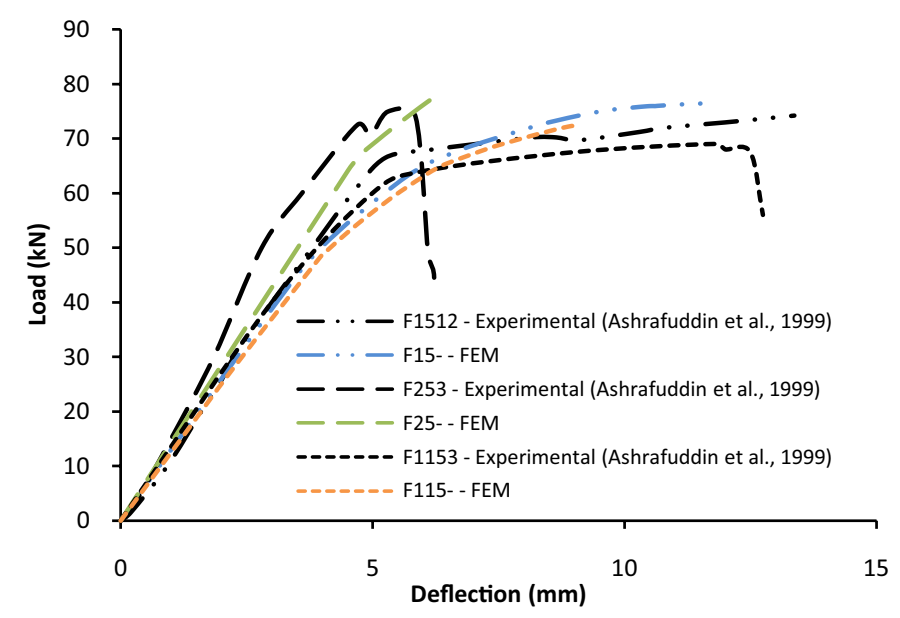

Fig. 10. Load versus central deflection verification and validation.

for other sets); the relevant beam is safe in shear capacity. Thereby, this observation verifies that the FE model is not designed to fail in shear and is considered safe in this aspect.

\section{Conclusions}

It is shown that, depending on the nature of stresses and direction of propagation of cracks, different modes of failures are originated as a consequence of mainly two types of cracks, which are interfacial crack and flexural crack. For example, Fig. 1 highlights two types of failures that can occur at the same location at plate-end, which are debonding and peeling. Noteworthy is the fact that, a CZM is effectively validated to show various flexural cracks that can propagate into forming interfacial debondings; this is used to identify standalone flexural cracks and FC cracks that can lead to debonding. Meanwhile, the implementation of a traction-separation approach and utilization of a damage parameter are found to demonstrate the direction of propagation of interfacial $\operatorname{crack}(\mathrm{s})$.

A large range of variables, such as different beam sizes, material properties, shear-span to depth ratio, adhesive line thickness, plate thickness, plate length and covercrete thickness affect the overall behavior of a beam with different modes of failure. As expected, the behavior of an under reinforced unplated beam is influenced by the material properties of a concrete in compression, whereas a plated beam increases its dependency on external plate with increase in its thickness (overall steel in tension). For example, a reduction in plate thickness reduces the load carrying capacity and stiffness of a beam, whereas an attempt to increase capacity of a beam by increasing plate-thickness is seen to couple with premature failure (for balanced to over-reinforced beams), from otherwise a ductile failure (for overall under-reinforced beams). 
In terms of crack types, sequence and behaviors (load and location of initiation and propagation), FE model is in close agreement with literature; and particularly, at tension region all such cracks that primarily lead to debonding and peeling. With regards to capacity in shear, the validation studies for the specimens of Ashrafuddin [1995], indicate that the closest agreement of numerical model is established for the specimens with closely spaced shear-stirrups. Capture of a DC crack by FE model (without shear stirrups) further affirms the findings of Oehlers [Oehlers (2001)], that the shear reinforcement is ineffective to prevent crack from initiating. As the present numerical model is a tool targeting premature cracks in plated RC beam; therefore, this maintains on the fact that a shear failure is rather due to insufficient shear reinforcement. Exceptional cases of Jones et al. [1982] are also studied; comparisons indicate that it is due to a relatively longer shear span for its crosssectional dimensions, a premature failure by peeling is not noted, whereas such a mode of failure is apparent for the specimens of Oh et al. [2003b], having different cross-section and length.

A peeling crack is distinguished from a debonding crack with the identification of stress types and location of stress concentration. Even though, the two types of failure can originate at same location (such as a plate-end), peeling tends to initiate as a consequence of flexural crack at plate-end, whereas debonding occurs due to relatively weaker interface for a given level of stress concentrations. This interface lies adjacent to pure interfaces of concrete-adhesive or adhesive-steel.

\section{Acknowledgment}

The present work is part of corresponding author's Ph.D. thesis, funded ${ }^{\mathrm{a}}$ by the School of Civil and Building Engineering and submitted under the supervision of Dr. Jamal El-Rimawi, Prof. Vadim V. Silberschmidt at Loughborough University (UK). The author would also like to express his gratitude towards his supervisors for providing excess to required facilities and research group (Mechanics of Advanced Materials) at the School of Mechanical and Manufacturing Engineering, Loughborough University (UK).

\section{Appendix}

\section{Modeling of Concrete in Compression}

Initially, for compression concrete a quadratic curve is assumed as:

$$
\sigma_{\text {parabola }}=A \epsilon^{2}+B \epsilon+C,
$$

where $C=0$ at origin, and at the beginning of the peak of plateau $\left(\epsilon_{o}, f_{c}^{\prime}\right), A=$ $-f_{c}^{\prime} / \epsilon_{o}^{2}$ and $B=2 f_{c}^{\prime} / \epsilon_{o}$.

\footnotetext{
${ }^{\text {a }}$ Financial support — Research Studentship, Loughborough University, UK.
} 


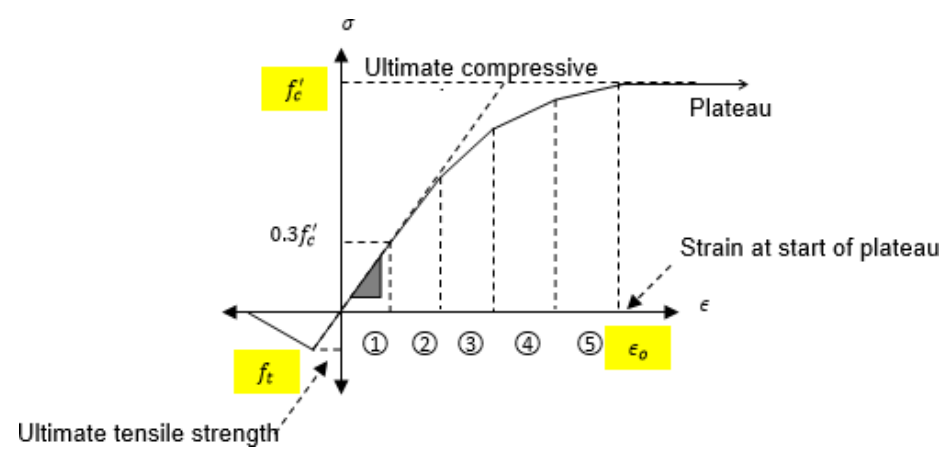

Fig. A.1. Simplified compressive uniaxial stress-strain relationship.

For a five-step simplified model (see Fig. A.1), the linear equation is assumed as follows; at origin $(0,0), F=0$ :

$$
\sigma_{\text {linear }}=D \epsilon+F \text {. }
$$

At first common point $\left(\epsilon_{1}, 0.3, f_{c}^{\prime}\right)$, parabolic and linear equations are equated to yield the value of $\epsilon_{1}$ :

$$
\epsilon_{1}=0.16 \epsilon_{o}
$$

If the compression stress (maximum at plateau, $f_{c}^{\prime}$ ) and strain (at the beginning of plateau, $\left.\epsilon_{o}\right)$ are known, then $E_{1}$ is evaluated as:

$$
E_{1}=0.3 f_{c}^{\prime} / \epsilon_{1}=D
$$

Substituting value for $\epsilon_{1}$ in the above equation

$$
E_{1} \approx 2 f_{c}^{\prime} / \epsilon_{o}=B
$$

Noteworthy is that, only two (and not three) of the variables $(\sigma, \epsilon$, or $E$ ) are regulated to lie within the available literature [Jansen and Shah (1997)] for a practical range, where $E$ is initial modulus.

After adjusting the first point for a five-step solution, the further steps (until the beginning of plateau $\left(\epsilon_{o}, f_{c}^{\prime}\right)$, that is at the end of parabola) are equally partitioned:

$$
\epsilon_{i}=\epsilon_{1}+(i-1)\left(\epsilon_{o}-\epsilon_{1}\right) / 4,
$$

where $i$ is step number of five-step material behavior; at $f_{c}^{\prime}, \epsilon_{5}=\epsilon_{o}$.

For $i>1$, stress is evaluated using a quadratic equation at strain $\epsilon_{i}$ :

$$
\sigma_{i}=\left(2 \epsilon_{i} / \epsilon_{o}-\left(\epsilon_{i} / \epsilon_{o}\right)^{2}\right) f_{c}^{\prime} .
$$

Abaqus plastic-strain is required in the form:

$$
\tilde{\epsilon}_{t, i}^{\mathrm{pl}}=\epsilon_{i}-\sigma_{i} / E_{1},
$$

where $i=$ step number. 
A change in modulus with each increment is evaluated as:

$$
E_{i}=\left(\sigma_{i}-\sigma_{i-1}\right) /\left(\epsilon_{i}-\epsilon_{i-1}\right),
$$

where $i$ (step number) $>1$.

\section{References}

ABAQUS [2011] ABAQUS Documentation, Dassault Systèmes, Providence, RI, USA.

Adhikary, B. B. and Mutsuyoshi, H. [2002] "Numerical simulation of steel-plate strengthened concrete beam by a non-linear finite element method model," Constr. Build. Mater. 16, 291-301.

Adhikary, B. B., Mutsuyoshi, H. and Sano, M. [2000] "Shear strengthening of reinforced concrete beams using steel plates bonded on beam web: Experiments and analysis," Constr. Build. Mater. 14, 237-244.

Alfano, G., De Cicco, F., Prota, A., Manfredi, G. and Cosenza, E. [2010] "Finite-element modeling via a cohesive-zone approach of reinforcedconcrete beams strengthened with fiber-reinforced polymers," in Safety, Reliability and Risk of Structures, Infrastructures and Engineering Systems (Taylor \& Francis Group, London), pp. 2025-2032.

Alfano, G., Rosati, L. and Simonelli, G. [2005] "Modelling of failure mechanisms in rc beams retrofitted with frp in flexure," VIII Int. Conf. Computational Plasticity, CIMNE, Barcelona, eds. Onate, E. and Owen, D. R. J., pp. 1-4.

Ali, M. S. M., Oehlers, D. J. and Park, S.-M. [2001] "Comparison between FRP and steel plating of reinforced concrete beams," Compos. A, Appl. Sci. Manuf. 32, 1319-1328.

Almusallam, T. H. and Al-Salloum, Y. A. [2001] "Ultimate strength prediction for RC beams externally strengthened by composite materials," Compos. B, Eng. 32, 609619.

Arslan, G., Sevuk, F. and Ekiz, I. [2008] "Steel plate contribution to load-carrying capacity of retrofitted RC beams," Constr. Build. Mater. 22, 143-153.

Ascione, L. and Feo, L. [2000] "Modeling of composite/concrete interface of RC beams strengthened with composite laminates," Compos. B, Eng. 31, 535-540.

Ashrafuddin, M. [1995] Prediction of Shear/Peeling Failure in Plated R/C Beams, M.Sc., King Fahd University of Petroleum and Minerals, Dhahran, Saudi Arabia.

Ashrafuddin, M., Baluch, M. H., Sharif, A., Al-Sulaimani, G. J., Azad, A. K. and Khan, A. R. [1999] "Peeling and diagonal tension failures in steel plated R/C beams," Constr. Build. Mater. 13, 459-467.

Bangash, M. Y. H. [1989] Concrete and Concrete Structures: Numerical Modeling and Applications (Elsevier Science Publishers Ltd., London, England).

Bontempi, F. M. and Malerba, P. G. [1997] "The role of softening in the numerical analysis of RC framed structures," Struct. Eng. Mech. 5, 785-801.

British Standard Institution [1990] in Steel, Concrete and Composite Bridges, "Code of practice for design of concrete bridges," (British Standards Institution, London, BS5400-4).

Charif, A. [1983] Structural Behavior of Reinforced Concrete Beams Strengthened by Epoxy Bonded Steel Plates, Ph.D. Thesis, The University of Sheffield, United Kingdom.

Chen, G., Teng, J. and Chen, J. [2011] "Finite-element modeling of intermediate crack debonding in FRP-plated RC beams," J. Compos. Constr. 15, 339-353.

Coronado, C. [2006] Characterization, Modeling and Size Effect of Concrete-Epoxy Interfaces, Ph.D. Thesis, The Pennsylvania State University, USA.

Coronado, C. and Lopez, M. [2010] "Numerical modeling of concrete-FRP debonding using a crack band approach," J. Compos. Constr. 14, 11-21. 
Coronado, C. A. and Lopez, M. M. [2006] "Sensitivity analysis of reinforced concrete beams strengthened with FRP laminates," Cement Concrete Compos. 28, 102-114.

De Lorenzis, L. and Zavarise, G. [2009] "Cohesive zone modeling of interfacial stresses in plated beams," Int. J. Solids Struct. 46, 4181-4191.

Godat, A., Labossière, P. and Neale, K. W. [2012] "Numerical investigation of the parameters influencing the behaviour of FRP shear-strengthened beams," Constr. Build. Mater. 32, 90-98.

Hamoush, S. A. and Ahmad, S. H. [1990a] "Debonding of steel plate-strengthened concrete beams," J. Struct. Eng. 116, 356-371.

Hamoush, S. A. and Ahmad, S. H. [1990b] "Static strength tests of steel plate strengthened concrete beams," Mater. Struct. 23, 116-125.

Heathcote, P. M. [2004] Theoretical and Experimental Study on FRP or Steel Plated RC Beams, Ph.D. Thesis, Loughborough University, United Kingdom.

Hussain, M., Sharif, A., Basunbul, I. A., Baluch, M. H. and Al-Sulaimani, G. J. [1995] "Flexural behavior of precracked reinforced concrete beams strengthened externally by steel plates," ACI Struct. J. 92, 14-22.

Jansen, D. and Shah, S. [1997] "Effect of length on compressive strain softening of concrete," J. Eng. Mech. 123, 25-35.

Jones, R., Swamy, R. N. and Ang, T. H. [1982] "Under- and over-reinforced concrete beams with glued steel plates," Int. J. Cem. Compos. Lightweight Concr. 4, $19-32$.

Jones, R., Swamy, R. N. and Charif, A. [1988] "Plate separation and anchorage of reinforced concrete beams strengthened by epoxy-bonded steel plate," The Struct. Eng. 66, 8594.

Jumaat, M. Z. and Alam, A. [2008] "Experimental and analytical investigations on the structural behaviour of steel plate and CFRP laminate flexurally strengthened reinforced concrete beams," J. Appl. Sci. 8, 4383-4389.

Kachlakev, D. I., Miller, T. H., Yim, S., Chansawat, K. and Potisuk, T. [2001] "Finite element modeling of concrete structures strengthened with frp laminates," Final Report FHWA-OR-RD-01-17, SPR 316, ed. Salem, Oregon, US.

Khan, M. A. [2014] FE Investigation of Failure Modes at the Soffit of a Steel Plated RC Beam, Ph.D. Thesis, Loughborough University, United Kingdom.

L'Hermite, R. and Bresson, J. [1967] "Beton arme d'armatures Collees" ("Concrete reinforced with glued plates"), RILEM Int. Symp. Synthetic Resins in Building Construction, Paris, September 1967, pp. 175-303.

Lee, J. and Fenves, G. L. [1998] "Plastic-damage model for cyclic loading of concrete structures," J. Eng. Mech. 124, 892-900.

Lubliner, J., Oliver, J., Oller, S. and Oñate, E. [1989] "A plastic-damage model for concrete," Int. J. Solids Struct. 25, 299-326.

Mahjoub, R. and Hashemi, S. H. [2010] "Finite element analysis of RC beams strengthened with FRP sheets under bending," Aust. J. Basic Appl. Sci. 4, 773-778.

Neto, P., Alfaiate, J., Dias-da-Costa, D. and Vinagre, J. [2016] "Mixed-mode fracture and load misalignment on the assessment of FRP-concrete bond connections," Compos. Struct. 135, 49-60.

Oehlers, D. J. [1992] "Reinforced concrete beams with plates glued to their soffits," J. Struct. Eng. 118, 2023-2038.

Oehlers, D. J. [2001] "Development of design rules for retrofitting by adhesive bonding or bolting either FRP or steel plates to RC beams or slabs in bridges and buildings," Compos A, Appl. Sci. Manuf. 32, 1345-1355. 
Oehlers, D. J., Mohamed Ali, M. S. and Luo, W. [1998] "Upgrading continuous reinforced concrete beams by gluing steel plates to their tension faces," J. Struct. Eng. 124, $224-232$.

Oehlers, D. J. and Moran, J. P. [1990] "Premature failure of externally plated reinforced concrete beams," J. Struct. Eng. 116, 978-995.

Oehlers, D. J., Park, S. M. and Mohamed Ali, M. S. [2003] "A structural engineering approach to adhesive bonding longitudinal plates to RC beams and slabs," Compos. A, Appl. Sci. Manuf. 34, 887-897.

Oh, B., Cho, J. and Park, D. [2003a] "Failure behavior and separation criterion for strengthened concrete members with steel plates," J. Struct. Eng. 129, 1191-1198.

Oh, B., Cho, J. and Park, D. [2003b] "Static and fatigue behavior of reinforced concrete beams strengthened with steel plates for flexure," J. Struct. Eng. 129, 527-535.

Rahimi, H. and Hutchinson, A. [2001] "Concrete beams strengthened with externally bonded FRP plates," J. Compos. Constr. 5, 44-56.

Raoof, M. and Hassanen, M. A. H. [2000] "Peeling failure of reinforced concrete beams with fibre-reinforced plastic or steel plates glued to their soffits," Proc. ICE - Structures and Buildings, Vol. 140, pp. 291-305.

Raoof, M., El-Rimawi, J. A. and Hassanen, M. A. H. [2000] "Theoretical and experimental study on externally plated RC beams," Eng. Struct. 22, 85-101.

Roberts, T. M. [1989] "Approximate analysis of shear and normal stress concentrations in the adhesive layer of plated RC beams," Struct. Eng. 67, 229-233.

Saadatmanesh, H. and Ehsani, M. [1991] "RC beams strengthened with GFRP plates. I: experimental study," J. Struct. Eng. 117, 3417-3433.

Saadatmanesh, H. and Malek, A. M. [1998] "Design guidelines for flexural strengthening of RC beams with FRP plates," J. Compos. Constr. 2, 158-164.

Sevuk, F. and Arslan, G. [2005] "Retrofit of damaged reinforced concrete beams by using steel plate," ASCE, Structures Congress 2005, New York, USA, April 20-24, pp. 1-8.

Shah, S. P., Swartz, S. E. and Ouyang, C. [1995] Fracture Mechanics of Concrete: Applications of Fracture Mechanics to Concrete, Rock and Other Quasi-Brittle Materials (John Wiley \& Sons, New York, USA).

Shanmugam, N. E. and Baskar, K. [2008] "Ultimate load behaviour of webs in steelconcrete composite plate girders," IES J. A, Civ. Struct. Eng. 1, 123-140.

Sharif, A., Al-Sulaimani, G. J., Basunbul, I. A., Baluch, M. H. and Ghaleb, B. N. [1994] "Strengthening of initially loaded reinforced concrete beams using FRP plates," Struct. J. 91, 160-168.

Smith, S. T. and Teng, J. G. [2001] "Interfacial stresses in plated beams," Eng. Struct. 23, 857-871.

Smith, S. T. and Teng, J. G. [2002a] "FRP-strengthened RC beams. I: Review of debonding strength models," Eng. Struct. 24, 385-395.

Smith, S. T. and Teng, J. G. [2002b] "FRP-strengthened RC beams. II: Assessment of debonding strength models," Eng. Struct. 24, 397-417.

Smith, S. T. and Teng, J. G. [2003] "Shear-bending interaction in debonding failures of FRP-plated RC beams," Adv. Struct. Eng. 6, 183-199.

Swamy, R. N., Jones, R. and Bloxham, J. W. [1987] "Structural behavior of reinforced concrete beams strengthened by epoxy-bonded steel plates," Struct. Eng. 65A, 59-68.

Swamy, R. N., Jones, R. and Charif, A. [1989] "The effect of external plate reinforcement on the strengthening of structurally damaged RC beams," The Struct. Eng. 67, 45-56.

Teng, J. G., Smith, S. T., Yao, J. and Chen, J. F. [2003] "Intermediate crack-induced debonding in RC beams and slabs," Constr. Build. Mater. 17, 447-462. 
Teng, J. G. and Yao, J. [2007] "Plate end debonding in FRP-plated RC beams - II: Strength model," Eng. Struct. 29, 2472-2486.

Teng, J. G., Zhang, J. W. and Smith, S. T. [2002] "Interfacial stresses in reinforced concrete beams bonded with a soffit plate: A finite element study," Constr. Build. Mater. 16, $1-14$.

Yang, Z. J., Chen, J. F. and Proverbs, D. [2003] "Finite element modelling of concrete cover separation failure in FRP plated RC beams," Constr. Build. Mater. 17, 3-13.

Yao, J. [2004] Debonding Failures in RC Beams and Slabs Strengthened with FRP Plates, M.Sc. Thesis, Hong Kong Polytechnic University, Hong Kong.

Ye, J. Q. [2001] "Interfacial shear transfer of RC beams strengthened by bonded composite plates," Cem. Concrete Compos. 23, 411-417.

Zhang, S., Raoof, M. and Wood, L. A. [1995] "Prediction of peeling failure of reinforced concrete beams with externally bonded steel plates," Proc. ICE - Structures and Buildings, Vol. 110, pp. 257-268.

Ziraba, Y. N. and Baluch, M. H. [1995] "Computational model for reinforced concrete beams strengthened by epoxy bonded steel plates," Finite Elem. Anal. Des. 20, 253271.

Ziraba, Y. N., Baluch, M. H., Basunbul, I. A., Sharif, A. M., Azad, A. K. and Al-Sulaimani, G. J. [1994] "Guidelines toward the design of reinforced concrete (RC) beams with external plates," ACI Struct. J. 91, 639-646. 